Tropical Journal of Pharmaceutical Research April 2017; 16 (4): 737-742

ISSN: $1596-5996$ (print); 1596-9827 (electronic)

(C) Pharmacotherapy Group, Faculty of Pharmacy, University of Benin, Benin City, 300001 Nigeria.

All rights reserved.

Available online at http://www.tjpr.org

Original Research Article

http://dx.doi.org/10.4314/tjpr.v16i4.1

\title{
Preparation and evaluation of peptide-dendrimer-paclitaxel conjugates for treatment of heterogeneous stage 1 non- small cell lung cancer in 293T and L132 cell lines
}

\author{
Wei-wei Zhang ${ }^{1}$, Yan-chun Wang ${ }^{1}$, Xiang-ming Kan ${ }^{1}$, Xue-mei Wang ${ }^{2}$ and Dong- \\ mei Geng ${ }^{1 *}$ \\ ${ }^{1}$ Department of Medical Oncology, Yanta Yuhuangding Hospital, Yantai, Shandong, 64000, 2Department of CT-MRI Room, \\ Longkou People's Hospital, Longkou 265701, Shandong, China \\ *For correspondence: Email: gengdongmei328@hotmail.com; Tel/Fax: 0086-535-6691999-81903
}

Received: 2 November 2016

Revised accepted: 9 March 2017

\begin{abstract}
Purpose: To develop peptide-dendrimer-paclitaxel conjugates for the treatment of heterogeneous stage 1 non small cell lung cancer (NSCLC) in 293T and L132cell line.

Method: Dendrimer-paclitaxel conjugates (PAMAM-PTX) were prepared by NHS method and the conjugates were used for the synthesis of peptide-dendrimer-paclitaxel conjugates (GE-PAMAM-PTX). The particle sizes of PAMAM-PTX and GE-PAMAM-PTX were measured. Entrapment efficiency of PTX in PAMAM-PTX was measured while GE-PAMAM-PTX. PTX release from PAMAM-PTX and GE$P A M A M-P T X$ was determined using a dialysis bag in $\mathrm{pH} 7.4$ phosphate buffer. The cytotoxicity of PAMAM-PTX, GE-PAMAM-PTX, PAMAM and PTX was evaluated by 3-(4,5-dimethylthiazol-2-YI)-2,5diphenyltetrazolium bromide (MTT) assay using 293T cell lines. In vitro cellular uptake assay of PAMAM-PTX and GE-PAMAM-PTX and PTX at concentrations ranging from 0.01 to $0.5 \mu M$ for $8 \mathrm{~h}$ was carried out in NSCLC cell lines 293T and L132.

Results: More than $95 \%$ entrapment efficiency of GE-PAMAM-PTX was observed with loading efficiency of $25 \%$. GE-PAMAM-PTX conjugates showed sustained release of PTX ( 85\%) towards the end of $50 \mathrm{~h}$. GE-PAMAM-PTX conjugates were more cytotoxic than pure PTX and PAMAM-PTX conjugates. The remarkable uptake of GE-PAMAM-PTX appear to be due to receptor-mediated endocytosis in the cell lines. The presence of ligand (GE) on PAMAM-PTX surface enabled the complex to bind to the over-expressed receptors on the cell lines.

Conclusion: GE-PAMAM-PTX can facilitate targeting of paclitaxel to lung cancer cell lines and tumors and facilitate release of the drugs in a sustained manner to improve the therapeutic efficacy of PTX.
\end{abstract}

Keywords: Paclitaxel, Lung cancer, Non-small cell lung cancer, Dendrimer, Peptide, PAMAM

Tropical Journal of Pharmaceutical Research is indexed by Science Citation Index (SciSearch), Scopus, International Pharmaceutical Abstract, Chemical Abstracts, Embase, Index Copernicus, EBSCO, African Index Medicus, JournalSeek, Journal Citation Reports/Science Edition, Directory of Open Access Journals (DOAJ), African Journal Online, Bioline International, Open-J-Gate and Pharmacy Abstracts

\section{INTRODUCTION}

Lung cancer is also known as pulmonary carcinoma. Lung cancer is characterized by the uncontrolled growth of cells in the tissues of lung. In developed and under developed countries nearly $25 \%$ deaths are due to cancer among which lung cancer is found as a major cause of mortality [1]. Lung cancers can be broadly divided in to small cell lung carcinoma (SCLC) and non-small cell lung carcinoma (NSCLC). It has been found that about $85-90 \%$ of lung cancer patients are histologically diagnosed with NSCLC [2,3]. Currently, chemotherapy, surgery, radiation therapy or combinations of these are the best treatment options for patients suffering 
from NSCLC. Among these available treatment options chemotherapy and radiation therapy has very little success rate for the treatment of NSCLC [4]. Unfortunately, presently available treatment options have limited tumor killing potential and also suffer from serious systemic toxicity. The major problem associated with current chemotherapy is nonspecific tumor targeting that kills normal cells as well severe side effects in patients with NSCLC [5].

Polyamidoamine (PAMAM) dendrimers are found to be potential drug carrier in cancers targeted drug delivery system. Dendrimers are widely applied in drug delivery technology due to their excellent monodispersed, hyper branched, three dimensional, tree like host-guest entrapment properties Dendrimers are extensively used in pharmaceutical, biotechnological applications to deliver biomolecules [6]. PAMAM dendrimers can be easily modified at the terminal amine groups by acetylation or PEGylation so as to improve their specific targeting to tumor cells [7].

Over expression of epidermal growth factor receptor (EGFR) of about 40 to $80 \%$ has been detected in NSCLC. GE11 is a peptide with high affinity for overexpressed EGFR tumor cells [8]. Specific targeting capability of PAMAM dendrimers can be improved by various targeting molecules such as folic acid, biotin, antibodies, peptides and carbohydrates [9-11]. Liu et al successfully developed peptide dendrimer conjugates as drug carriers for NSCLC [12]. Also Cheng et al developed GEII modified liposomes for NSCLC targeting [13]. Apart from this, Long et al have developed doxorubicin encapsulated EGF surface modified gelatin nanoparticles to target EGFR overexpressed in lung cancer tissue [14]. In the present study we have used paclitaxel (PTX) as a model anticancer drug which is a first line chemotherapeutic agent that works by disrupting normal microtubule breakdown while the cell divides. The major difficulty with the drug is that it is poorly soluble in water. Therefore, it is necessary to develop an alternate delivery system for PTX with the aim of increasing its availability and maximize its therapeutic value [15].

\section{EXPERIMENTAL}

\section{Materials}

Paclitaxel was obtained from Afine Chemicals Limited, China. Acetylated PAMAM G3 dendrimer was procured from Sigma Aldrich, USA. GE11 peptide with terminal cysteine was procured from GL Biochem Ltd (Shanghai, People's Republic of China).

\section{Preparation of dendrimer-paclitaxel conjugates (PAMAM-PTX)}

The synthesis of dendrimer-paclitaxel conjugate was as described by Teow et al. Covalent attachment of lauryl chains to the surface of dendrimers (PAMAM G3) was done by activating lauryl chain to lauryl 4-nitrophenyl carbonate. The lauryl 4-nitrophenyl carbonate was reacted with amine groups of dendrimers present on the terminal surface (PAMAMG3 at the appropriate molar ratio) to obtain lauryl-G3PAMAM dendrimers. The N-hydroxysuccinimide (NHS) method (through a glutaric anhydride linker) was used to form paclitaxel lauryl-G3 PAMAM dendrimer conjugate. Paclitaxel was reacted with glutaric anhydride to produce 2'-glutarylpaclitaxel. Then it was converted to paclitaxelglutaryl-NHS ester, followed by equimolar conjugation with lauryl-G3 PAMAM dendrimers to produce PAMAM-PTX conjugates [16].

\section{Synthesis of peptide-dendrimer-paclitaxel conjugates (GE-PAMAM-PTX):}

GE11 peptide with terminal cysteine $(9.2 \mathrm{mg})$ was dissolved in $1.5 \mathrm{~mL}$ DMSO solution and it was added drop wise to the solution containing dendrimer -paclitaxel conjugates (PAMAM-PTX). The solution was stirred overnight on magnetic stirrer and the crude product was dialyzed using dialysis membrane (molecular weight cut off $=$ $3500 \mathrm{Da}$ ). Removal of peptide was ensured by measuring absorbance at $280 \mathrm{~nm}$. The product obtained was lyophilized in a dark room for $24 \mathrm{~h}$ to yield free-flowing powder of peptidedendrimer-paclitaxel conjugates [13].

\section{Particle size}

The particle size of PAMAM-PTX and GEPAMAM-PTX was measured in a Zetasizer (Malvern instruments DTS Ver 4.10).

\section{PTX conjugation efficiency (CE)}

The PAMAM-PTX and GE-PAMAM-PTX were centrifuged separately and the amount of nonconjugated PTX (free drug) was measured in the clear supernatant using HPLC. Conjugation efficiency (CE) of the PTX from PAMAM-PTX and GE-PAMAM-PTX were calculated as in Eq 1 [13].

$\%$ C.E $=\{(T d-F d) / T d\} 100$

Where $\mathrm{Td}$ and $\mathrm{Fd}$ are the total and free (unconjugated) drug, respectively.

\section{In vitro PTX release study}


PTX release from PAMAM-PTX and GEPAMAM-PTX was determined using dialysis bag with magnetic stirring. PAMAM-PTX and GEPAMAM-PTX conjugates (15 mg) were dispersed separately in $5 \mathrm{~mL} \mathrm{pH} 7.4$ phosphate buffer and placed in a dialysis membrane bag tied on both ends and placed into $200 \mathrm{~mL}$ PBS solution in a beaker. The temperature was maintained at 37 ${ }^{\circ} \mathrm{C}$ and whole system was kept on magnetic stirring. At specified time interval, $5 \mathrm{ml}$ of buffer solution was removed and replenished with fresh PBS solution to maintain the sink condition [16]. The amount of $\mathrm{PTX}$ in released into the medium was evaluated by HPLC.

\section{Cell culture}

NSCLC cell line 293T and L132 were purchased from Shanghai Institute of Cell Biology. Both cell lines were cultured in Roswell Park Memorial Institute-1640 (RPMI-1640) supplemented with $10 \%$ fetal bovine serum, $1 \%$ penicillin and 100 $\mu \mathrm{g} / \mathrm{ml}$ streptomycin sulphate at $37{ }^{\circ} \mathrm{C}$ in $5 \% \mathrm{CO}_{2}$.

\section{Cytotoxicity test}

The cytotoxicity of PAMAM-PTX and GEPAMAM-PTX, PAMAM and PTX was evaluated by MTT assay. 293T cells were seeded (at a density of $1 \times 10^{5}$ cells/well) into 96-well plates and incubated for $24 \mathrm{~h}$. The cells were incubated for $24 \mathrm{~h}$ with the test compound (PAMAM-PTX, GE-PAMAM-PTX, PAMAM and PTX) at 0.20 and $0.40 \mathrm{mg} / \mathrm{mL}$ concentrations. Thereafter, $1 \mathrm{mg} / \mathrm{mL}$ MTT was added and incubated for $1 \mathrm{~h}$ with the treated human lung cancer cell line 293T at 37 ${ }^{\circ} \mathrm{C}$. Amount of MTT converted to insoluble formazan dye by mitochondrial dehydrogenases determines the viable cells. The formed formazan crystals were dissolved in a $1 \mathrm{M} \mathrm{HCl}$ isopropyl alcohol mixture (1:24 v/v) and shaken for $20 \mathrm{~min}$ at room temperature [13].

\section{In vitro cellular uptake assay in NSCLC cell line 293T and L132}

Cell culture 24 well plates were used to seed 293T and L132 cells (density of $10^{5}$ cells/well). The cells were incubated with PAMAM-PTX, GEPAMAM-PTX and PTX at concentrations of 0.01 to $0.5 \mu \mathrm{M}$ for $8 \mathrm{~h}$. A $0.5 \mu \mathrm{M}$ concentration of conjugate was used for incubation of the cells for $4 \mathrm{~h}$, to compare the uptake efficiency between 293T and L132 cells. The cells were trypsinised at the end of incubation and washed with saline buffer three times. They were then centrifuged and treated with lysis buffer and sonicated. The internalized drug was quantified by measuring the supernatant solutions by HPLC [14].

\section{RESULTS}

The particle size analysis of both PAMAM-PTX and GE-PAMAM-PTX was determined by using Zetasizer (Malvern Instruments DTS, Ver 4.10). No significant difference was found between particle size of PAMAM-PTX and GE-PAMAMPTX. The particle size of PAMAM-PTX and GEPAMAM-PTX was 110 and $112.5 \mathrm{~nm}$, respectively. Furthermore, entrapment efficiency of both PAMAM-PTX and GE-PAMAM-PTX were more than $95 \%$ with effective loading efficiency of $25 \%$. Release of PTX from PAMAM-PTX and GE-PAMAM-PTX was done in phosphate buffered saline ( $\mathrm{pH}$ 7.4). As can be seen in Figure 1, 100\% unconjugated PTX was release within $10 \mathrm{~h}$ while initial rapid release of $\sim 15 \%$ was observed from both PAMAM-PTX and GEPAMAM-PTX conjugated system, followed by gradual sustained release of PTX ( 85\% in 50 h).

In vitro cytotoxicity data for human lung cancer cell line (Figure 2), indicate concentrationdependent cytotoxicity in $24 \mathrm{~h}$.

Cellular uptake results show that cellular uptake efficiencies of PTX and PAMAM-PTX were concentration-dependent for both cell lines, as shown in Figure 3. Uptake efficiency of GEPAMAM-PTX was much higher than that of PTX. PAMAM-PTX also showed 2.5 fold higher cellular internalization for both cell lines.

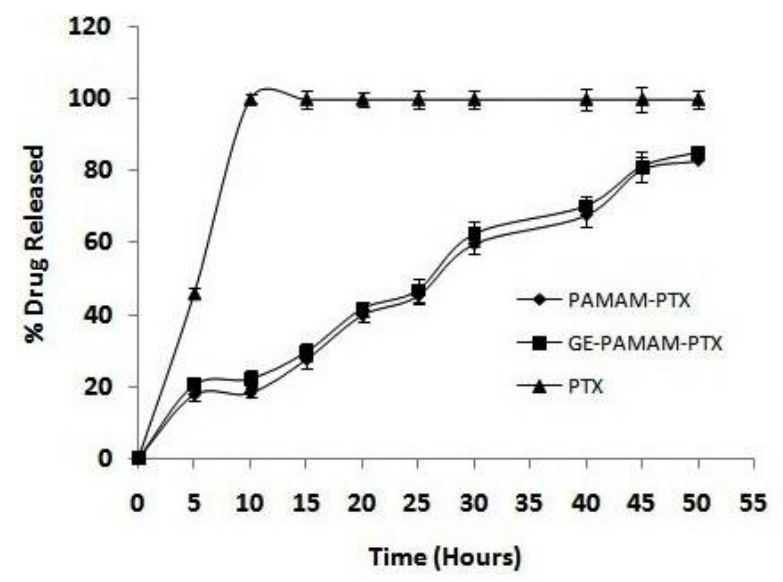

Figure 1: Comparative drug release profile of PAMAM-PTX, GE-PAMAM-PTX and PTX. No significant difference was observed between PAMAMPTX, GE-PAMAM-PTX indicating conjugation of peptide did not alter the release pattern of PAMAMPTX 

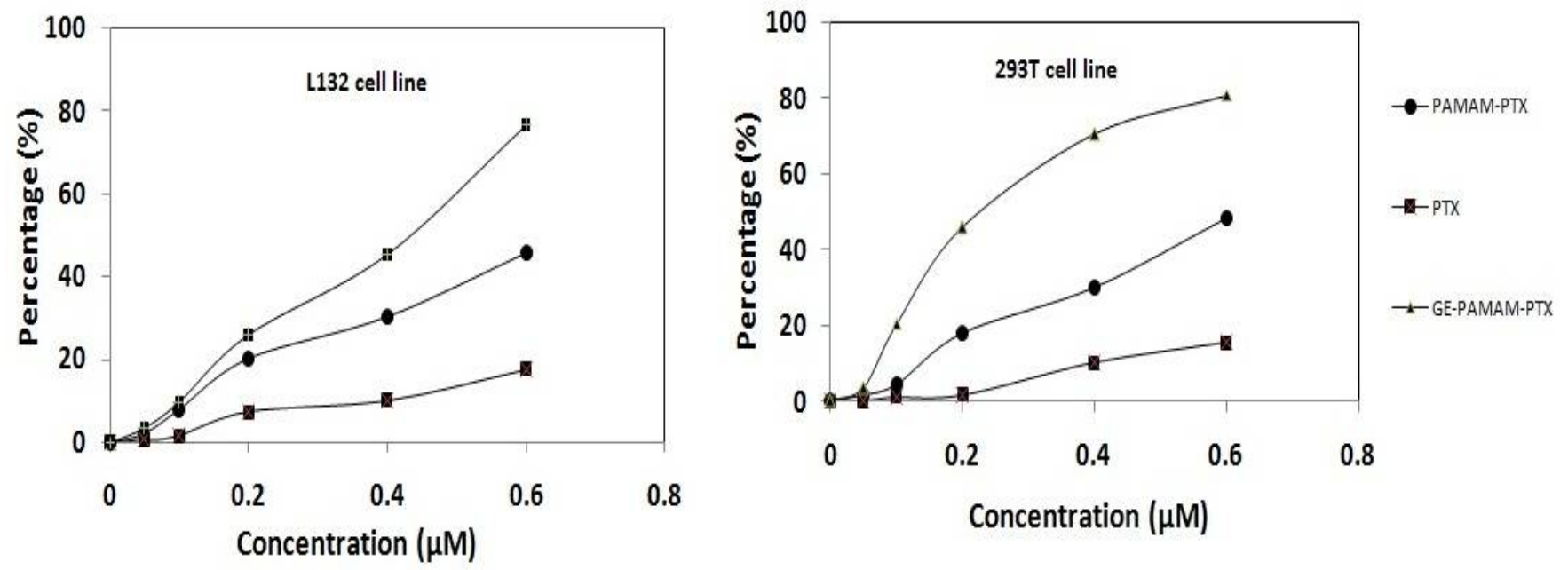

Figure 3: In vitro cellular uptake assay study on L132 cell line and 293T cell line

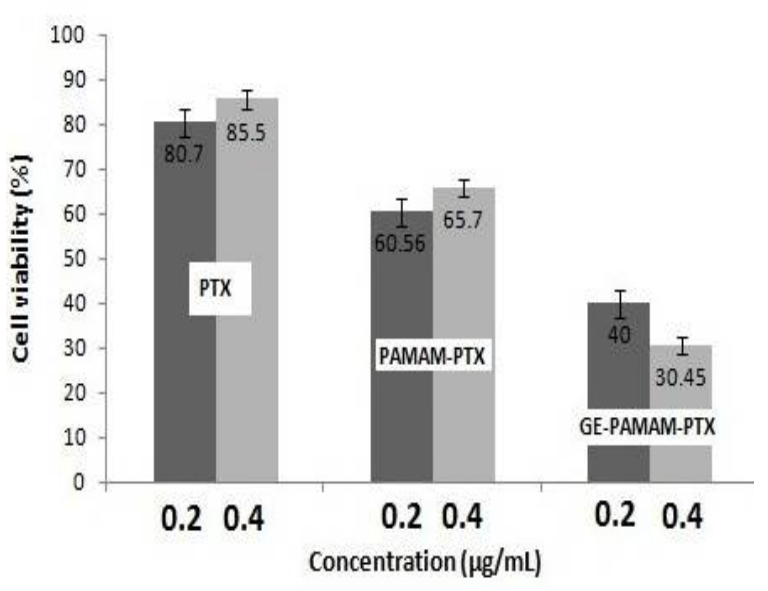

Figure 2: In vitro cytotoxic assay carried out in human lung cancer cell line 293T (MTT assay)

\section{DISCUSSION}

Smaller particle size of the carrier system plays vital role in distribution in cell culture and that leads to maximum cellular accumulation of drug. It is a well-known fact that smaller particles have maximum capacity to invade the lung tumour. The results indicate that addition of GE11 peptide on PAMAM-PTX conjugate did not alter the particle size distribution characteristics. The maximum entrapment efficiency of PTX was attributed to empty internal cavities of the dendrimer which easily accommodate the hydrophobic drug molecule in the macromolecule interior. PTX is a highly hydrophobic molecule which was successfully entrapped in the internal cavities of the PAMAM dendrimer [17]. The sustained release system used played an important role for availability of PTX in constant and steady manner to lung tumor. The drug release kinetics was studied by applying mathematical models like zero order, first order, Higuchi and Koremeyer- Peppas model. Out of these four models, Higuchi model $(r=0.992)$ was found to be the best fit indicating diffusion based drug release pattern. Koremeyer-Peppas which is a semi-empirical formula was used to describe the drug release mechanism. The ' $n$ 'value of 0.84 confirms the non-Fickian mode of release which suggests diffusion and erosion are the main mechanisms of action [18].

GE-PAMAM-PTX exhibited the greatest antiproliferative effect in this cell line as compared to that of PTX, PAMAM-PTX. Enhancement of antiproliferative effect of GE-PAMAM-PTX is attributed to enhanced cellular uptake. The conjugate system following endocytic uptake will rapidly escape from the endocytic compartments and reach the acidic lysosome. In this acidic environment PTX will be released continuously in a steady manner and diffuses into nuclear core complex. PTX works by disrupting the normal microtubule breakdown while the cell divides [19]. It is very essential to internalize nanoparticles into cancerous cells so that the drug will be released and is available for therapeutic action. However, the uptake capacity of the GE-PAMAM-PTX was much higher than that of PTX, and PAMAM-PTX, demonstrating a 2.5-fold higher cellular internalization. The remarkable uptake of GE-PAMAM-PTX is due to endocytosis mediated by receptors. The presence of ligand (GE) on PAMAM-PTX surface enabled the complex to bind to the overexpressed receptors on the cell lines. The remarkable lower cellular uptake observed for PTX, and PAMAM-PTX was due to non-specific adsorption or interaction with the cells [20].

\section{CONCLUSION}

Peptide-dendrimer-paclitaxel (GE-PAMAM-PTX) conjugates have been successfully developed to target epidermal growth factor receptor (EGFR) 
which are over-expressed in lung cancer tissue. The remarkable uptake of GE-PAMAM-PTX observed may be due to receptor-mediated endocytosis in the cell lines (L132 cell line and 293T cells). The presence of ligand (GE) on PAMAM-PTX surface enables the complex to bind to the over-expressed receptors on the cell lines. Overall, the results show that GE-PAMAMPTX can facilitate drug targeting to lung cancer cell line and tumors in a sustained manner and thus, improve the therapeutic efficacy of PTX. This targeted drug delivery system appears promising for lung cancer treatment.

\section{DECLARATIONS}

\section{Acknowledgement}

The authors are grateful to Department of Medical Oncology Yanta Yuhuangding Hospital, Yantai, Shandong, 64000, China for providing facilities to conduct this work.

\section{Conflict of Interest}

No conflict of interest associated with this work.

\section{Contribution of Authors}

The authors declare that this work was done by the authors named in this article and all liabilities pertaining to claims relating to the content of this article will be borne by them.

\section{Open Access}

This is an Open Access article that uses a funding model which does not charge readers or their institutions for access and distributed under the terms of the Creative Commons Attribution License (http://creativecommons.org/licenses/by/ 4.0) and the Budapest Open Access Initiative (http://www.budapestopenaccessinitiative.org/rea d), which permit unrestricted use, distribution, and reproduction in any medium, provided the original work is properly credited.

\section{REFERENCES}

1. Parkin DM, Bray F, Ferlay J, Pisani P. Global Cancer Statistics, 2002.CA Cancer J Clin 2005; 55: 74-108.

2. Rosell R, Felip E, Garcia-Campelo R, Balana C. The biology of non-small-cell lung cancer: identifying new targets for rational therapy. Lung Cancer. 2004; 46 : 135-148.

3. Califano $R$, Abidin AZ, Peck R, Faivre-Finn $C$, Lorigan $P$. Management of small cell lung cancer: recent developments for optimal care. Drugs 2012; 72: 471 490 .
4. Jemal A, Bray F, Center MM, Ferlay J, Ward E, Forman D: Global cancer stat. CA Cancer J Clin 2008; 61:6990.

5. Zarogoulidis P, Chatzaki E, Porpodis K, Domvri K, Hohenforst-Schmidt $W$, Goldberg EP, Karamanos $N$, Zarogoulidis K: Inhaled chemotherapy in lung cancer: future concept of nanomedicine. Int J Nanomed 2012; 7: 1551-1572.

6. Yang $W$, Cheng $Y, X u T$. Targeting cancer cells with biotin dendrimer conjugates. Eur J Med Chem 2009; 44(2): 862-868.

7. Majoros IJ, Myc A, Thomas T, Mehta CB and Baker JR. PAMAM dendrimer-based multifunctional conjugate for cancer therapy: synthesis, characterization, and functionality. Biomacromolecule 2006; 7: 572-579.

8. Koshkina NV, Waldrep JC, Roberts LE, Golunski E, Melton S, Knight V. Paclitaxel liposome aerosol treatment induces inhibition of pulmonary metastases in murine renal carcinoma model. Clin Cancer Res 2001; 7: 3258-3262.

9. Kojima C, Kono K, Maruyama K. Synthesis of polyamidoamine dendrimers having poly(ethylene glycol) grafts and their ability to encapsulate anticancer drugs. Bioconjug Chem 2000; 11(6): 910-917.

10. Venkata $V$, Venuganti $K$, Omathanu PP. Effect of poly(amidoamine) (PAMAM) dendrimer on skin permeation of 5-fluorouracil. Int J Pharm 2008; 361 : 230-238

11. Ma M, Cheng $Y, X u Z$, Xu P, Qu H, Fang $Y, X u T$, Wen $L$. Evaluation of polyamidoamine (PAMAM) dendrimers as drug carriers of anti-bacterial drugs using sulfamethoxazole (SMZ) as a model drug. Eur $J$ Med Chem 2007; 42: 93 e98

12. Liu J, Liu J, Chu L, Wang Y, Duan Y, Feng L, Yang C, Wang $L$, Kong $D$. Novel peptide-dendrimer conjugates as drug carriers for targeting non-small cell lung cancer. Int. J. Nanomedicine 2011; 6: 59-69

13. Cheng L, Huang F-Z, Cheng L-F, Zhu Y-Q, Hu Q, Li L, Wei $L$, Chen $D-W$. GE11-modified liposomes for nonsmall cell lung cancer targeting: preparation, ex vitro and in vivo evaluation. Int $J$ Nanomed 2014; 9: 921-935

14. Long. Anticancer drug-loaded multifunctional nanoparticles to enhance the chemotherapeutic efficacy in lung cancer metastasis. J Nanobiol. 2014; 12: 37.

15. Anon. Paclitaxel (taxol) for ovarian cancer. Med Lett Drugs Ther 1993; 35(896): 39-40.

16. Huey MT, Zhengyuan $Z$, Mohammad $N$, Siti $R$, D'Emanuelea A. Delivery of paclitaxel across cellular barriers using a dendrimer-based nanocarrier. Int $J$ Pharm 2013; 441: 701- 711

17. Majoros IJ, Myc A, ThomasT, Mehta CB, Baker JR. PAMAM dendrimer based multifunctional conjugate for cancer therapy: synthesis, characterization, and functionality. Biomacromolecule 2006; 7: 572-579.

18. Kim K, Kim JH, Park H, Kim YS, Park K, Nam H, Lee S, Park JH, Park RW, Kim IS, Choi K, Kim SY, Kwon IC: Tumor-homing multifunctional nanoparticles for cancer theragnosis: simultaneous diagnosis, drug delivery, and

Trop J Pharm Res, April 2017; 16(4): 741 
therapeutic monitoring. J Control Release 2010; 146 : 219-227.

19. Ballatore $C$, Zhang B, Trojanowski JQ, Lee VMY, Smith $A B$ (III). 2008. In situ blood-brain barrier permeability of a C-10 paclitaxel carbamate. Bioorg Med Chem Lett 2008; 18: 6119-6121.

20. Burris HA. Shortcomings of current therapies for nonsmall-cell lung cancer: unmet medical needs. Oncogene 2009; 28: S4-S13. 